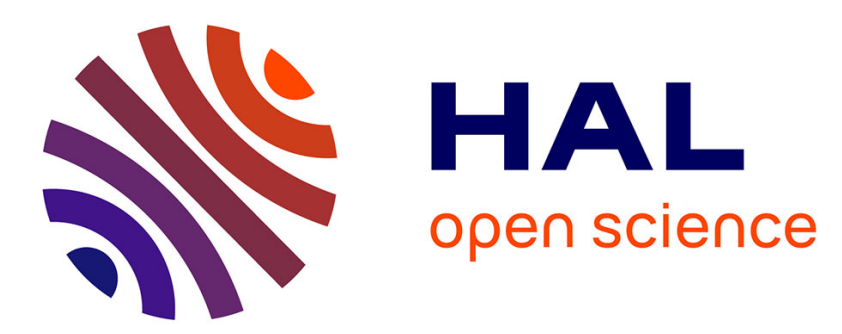

\title{
Development of the Analysis of Fecal Stanols in the Oyster Crassostrea gigas and Identification of Fecal Contamination in Shellfish Harvesting Areas
}

Loïc Harrault, Emilie Jardé, Laurent Jeanneau, Patrice Petitjean

\section{- To cite this version:}

Loïc Harrault, Emilie Jardé, Laurent Jeanneau, Patrice Petitjean. Development of the Analysis of Fecal Stanols in the Oyster Crassostrea gigas and Identification of Fecal Contamination in Shellfish Harvesting Areas. Lipids, 2014, 49 (6), pp.597-607. 10.1007/s11745-014-3908-5 . insu-01002609

HAL Id: insu-01002609

https://hal-insu.archives-ouvertes.fr/insu-01002609

Submitted on 6 Jun 2014

HAL is a multi-disciplinary open access archive for the deposit and dissemination of scientific research documents, whether they are published or not. The documents may come from teaching and research institutions in France or abroad, or from public or private research centers.
L'archive ouverte pluridisciplinaire HAL, est destinée au dépôt et à la diffusion de documents scientifiques de niveau recherche, publiés ou non, émanant des établissements d'enseignement et de recherche français ou étrangers, des laboratoires publics ou privés. 
Lipids:

2

3 Development of the analysis of fecal stanols in the oyster Crassostrea gigas and identification

4 of fecal contamination in shellfish harvesting areas

5

6 Loïc Harrault, Emilie Jardé*, Laurent Jeanneau and Patrice Petitjean

7

8 CNRS, UMR 6118 Geosciences Rennes, Campus de Beaulieu, 35042 Rennes Cedex, France

9

10 Keywords : Stanol analysis; Gas chromatography; Mass spectrometry; Oysters, Fecal 11 contamination, Microbial Source Tracking.

$13 \quad$ *corresponding author:

14 Email: emilie.jarde@univ-rennes1.fr

Phone: +33 (0)2.23.23.56.20 


\section{Abstract}

The objective of this work was to study the effects of washing and purification steps on qualitative and quantitative analysis of fecal stanols in the oyster Crassostrea gigas using either single or combination of lipid purification steps on silica gel or aminopropyl bonded silica gel $\left(\mathrm{NH}_{2}\right)$ or a washing step. Among the three analytical pathways compared, the two including water extraction or $\mathrm{NH}_{2}$ purification did not lead to higher recoveries and decreased repeatabilities of extractions compared to the single purification on silica gel. This latter led to similar recoveries (ca. 80\%) and repeatabilities (ca. 10\%) for both spiked standards (coprostanol and sitostanol). This analytical pathway has been applied to oysters collected in a harvesting area in Brittany (France) where fecal contaminations are important and allowed to quantify eight stanols in oysters. The relative proportions of fecal stanols of these oysters were combined with principal component analysis in order to investigate the usefulness of their stanol fingerprints to record a fecal contamination and to distinguish its source between human, porcine and bovine contaminations. Oysters non-fecally contaminated by Escherichia coli did not present specific stanol fingerprints while oysters fecally contaminated had a bovine fingerprint, suggesting a contamination of these samples by bovine sources. As a consequence, the method developed here allows the use of stanol fingerprints of oysters as a microbial source tracking tool that can be applied to shellfish harvesting areas subjected to fecal contaminations in order to identify the different sources of contamination and improve watershed management. 
39 Abbreviations

40 BSTFA N,O-bis- (trimethylsilyl)trifluoroacetamide

41 DCM Dichloromethane

42 DW Dry weight

43 GC-MS Gas chromatography- mass spectrometry

$44 \mathrm{MeOH} \quad$ Methanol

$45 \quad \mathrm{NH}_{2} \quad$ Aminopropyl-bonded silica gel

46 PCA Principal component analysis

47 TMCS Trimethylchlorosilane

48 


\section{Introduction}

51

Coastal and shellfish harvesting areas are subjected to fecal contaminations from human and animal waste leading to sanitary risks due to the presence of source-specific microbial pathogens in contaminated waters and shellfish $[1,2,3]$. Among shellfish, several species of bivalves such as mussels and oysters have been used as biological models for research in ecotoxicology and biomonitoring since they are suspension filter-feeders which may bioaccumulate and record environmental contaminants into their tissues [4, 5].

Fecal contamination of shellfish is particularly acute in France which is the first European producer of oysters (mainly Crassostrea gigas) [6]. In Brittany, one of the main areas of production of Crassostrea gigas, shellfish can be subjected to fecal contamination leading to the closure of shellfish harvesting areas [7]. Therefore, to limit i) sanitary risks linked to the consumption of contaminated shellfish and especially Crassostrea gigas and ii) economic loss due to the closure of shellfish harvesting areas, it is crucial to improve watershed management by controlling and limiting the sources of fecal contamination within these environments.

For this purpose, the actual European Shellfish Directive on shellfish harvesting (854/2004/EC) imposes the classification of shellfish and requires the assessment of potential pollution sources upstream of shellfish harvesting. The actual classification is based on the fecal indicator bacteria Escherichia coli and enterococci which are not species-specific.

In order to distinguish human and animal sources of fecal contamination within environment, microbial source tracking methods have been developed during the last decade. Based on specific microbial or chemical markers from human or animals, they have been successfully applied to field studies to identify the sources of fecal contamination in water, 
soil and sediment [7-16]. Among chemical markers, fecal stanols have proven their usefulness as direct fecal markers [17]. Indeed, the distribution of fecal stanols in animal faeces relies on three main factors: i) the animal's diet, ii) the ability of animals to biosynthesize endogenous sterols and iii) the composition of the intestinal flora responsible for sterol biohydrogenation into stanols. Consequently, the fecal stanol fingerprint allows to distinguish between different fecal sources in environmental matrix by the use of stanol ratios [18-20] or multivariate analyses [14, 15, 21, 22].

In Brittany, the main sources of fecal contamination in water are human wastewater treatment effluent, porcine and bovine manure or slurry [12]. In this region, the transfer time of water in coastal watersheds from streams to sea can last for one day [23] and it has been shown that a stanol fingerprint associated with a specific source of contamination can last for six days in fresh and seawaters microcosms [24, 25]. Therefore, the specificity of a stanol fingerprint can be transferred from inland waters to receiving seawater, which could allow the identification of the sources of fecal contamination in water in such areas [14, 20]. In shellfish harvesting areas, shellfish can bio-accumulate microbial pathogens by filtration of contaminated surrounding waters, which enables the identification of contamination sources using microbial markers [7]. However, it is still unknown whether chemical markers such as fecal stanols and corresponding stanol fingerprints allow the identification of fecal contamination sources in oysters.

Indeed, studies dealing with the occurrence of fecal stanols in shellfish mainly have focused on coprostanol as a marker of human fecal contamination in fresh or seawater mussels [26-31]. However, the identification of fecal sources with stanol fingerprints requires the accurate analysis of several compounds [14, 17, 22]. Therefore, it is necessary to develop an analytical pathway that allows the quantification of different fecal stanols in shellfish matrix, which constituted the first goal of the present study. 
Among the main studies focusing on coprostanol quantification in mussels, only Cathum and Sabik [27] have tested the extraction efficiency of their method and found recoveries of about $48 \%$ for wet mussel samples. As a consequence, the efficiencies of such methods remain largely unknown. In this present study, the efficiencies and repeatabilities of three analytical pathways have been compared for the stanol extraction of the oyster Crassostrea gigas using two recovery standards:

-The first method consisted of three steps: i) extraction of lipids from oyster matrix, ii) purification of lipids on silica gel and iii) analysis of stanol fraction by gas chromatographymass spectrometry (GC-MS).

-The second method comprised of a washing step of oyster tissue with water prior to lipid extraction. Indeed, shellfish such as oysters can be constituted of more than $90 \%$ of nonlipid compounds such as glycogen and proteins that can potentially interact with lipids and decrease their recoveries [32, 33]. Therefore, a washing step of matrix with water prior to the lipid extraction step allows the removal of the non-lipid compounds and could improve extraction efficiencies of stanols [34, 35].

-The third method comprised of a second purification step of lipids on aminopropylbonded silica gel after that on silica gel. The separation of lipid classes from the total extract is mandatory in complex environmental matrix to improve the analysis accuracy of target compounds. The lipid fraction of oysters is a complex mixture containing several lipid classes such as phospholipids, triacylglycerols, free fatty acids, sterols and stanols [36]. Therefore, the addition of a purification step could be particularly interesting in order to remove as much of lipids of non-interest as possible. Aminopropyl-bonded silica gel $\left(\mathrm{NH}_{2}\right)$ was chosen as the second sorbent because of its affinity and subsequent selective retention of acidic phospholipids [37]. 
To the best of our knowledge, no method has been developed for the analysis of several

fecal stanols in shellfish. Among the three methods tested here, the one leading to the highest and similar recoveries and highest repeatabilities for both recovery standards was chosen to analyse the concentration of several fecal stanols in oysters from northern Brittany, France. The stanol fingerprint of these oysters were analyzed by principal component analysis (PCA) in order to identify the fecal contamination sources in this shellfish harvesting area.

\section{Experimental}

\subsection{Reagent and chemicals}

Organic solvents were of high performance liquid chromatography grade. Dichloromethane (DCM) was purchased from Carlo-Erba SDS (Val de Reuil, France), methanol (MeOH) and cyclohexane were purchased from VWR (West Chester, PA). N,O-bis(trimethylsilyl)trifluoroacetamide and trimethylchlorosilane (99:1, by vol) (BSTFA + TMCS) and SPE disks (Supelco ENVI-18DSK, 47mm diameter) were purchased from Supelco (St.

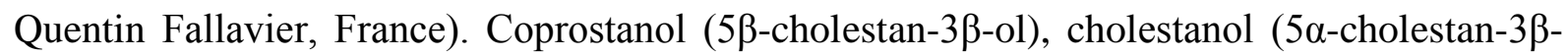
ol), 5 $\alpha$-cholestane and aminopropyl-bonded silica gel were purchased from Sigma (St. Quentin Fallavier, France). Sitostanol (24-ethyl-5 $\alpha$-cholestan-3 $\beta$-ol) was purchased from

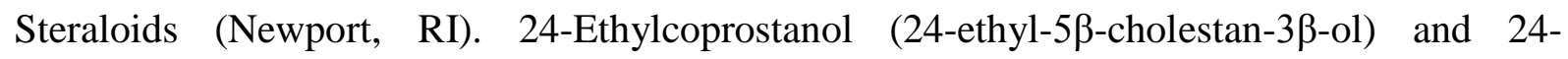

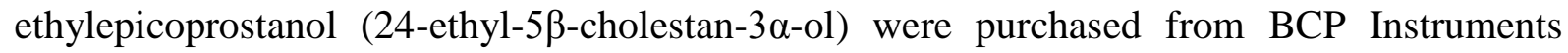
(Irigny, France). Silica gel (40-63 $\mu \mathrm{m})$ was purchased from Merck (Darmstadt, Germany). Cholesterol $d_{6}\left(\left[2,2,3,4,4,6-{ }^{2} \mathrm{H}_{6}\right]\right.$-cholest-5-en-3 $\beta$-ol) was purchased from CDN Isotopes (Pointe-Claire, Quebec, Canada).

\subsection{Sample preparation}


To compare the three analytical pathways, 90 oysters (Crassostrea gigas) were purchased at Cancale (Brittany, France) in November 2012. After purchasing, oysters were opened, the intervalvular liquid discarded, the flesh of 10 individuals were pooled as one sample (ca. $4 \mathrm{~g}$ of dry weight flesh), frozen, freeze-dried and finally ground with an agate mortar for homogenization.

As the main goal of this study is to analyse several fecal stanols in shellfish tissues, two recovery standards were used to determine the reliability of the tested methods. The common human marker coprostanol was the first one and sitostanol was chosen as the second recovery

155 standard because it is a fecal stanol rather representative of a bovine contamination [17]. Coprostanol and sitostanol were spiked on the freeze-dried flesh pool just before organic extraction (methods 1 and 3, see below) or aqueous extraction (method 2, see below) at a concentration of $10 \mu \mathrm{g} \mathrm{g}^{-1}$ dry weight (DW). This concentration is in the range of coprostanol concentration recorded in bivalves after human fecal contamination [26-31]. For both blanks and spiked samples, each extraction method was performed in triplicates.

\subsection{Application to a study case: the Fresnaye bay}

Among the three methods tested, the one leading to the better recoveries of spiked coprostanol and sitostanol and to better repeatabilities was used to determine the concentration and the distribution of fecal stanols of oysters from the Fresnaye bay (Brittany, France, Figure 1). This bay is an intensive shellfish harvesting area with an annual production of ca. 550 tons of Crassostrea gigas intended for human consumption. The Fresnaye watershed covers $121 \mathrm{~km}^{2}$ and its number of human inhabitants is estimated at 14000 . The potential sources of fecal contaminations originate from the seven wastewater treatment plants of the watershed and multiple sources of untreated wastewater, and its agricultural area covers ca. $70 \%$ of watershed area with intensive livestock farming of pigs (ca. 235.000 head in 
172 2010), and cows (ca. 5300 head in 2010) [38]. In the last decade, this shellfish harvesting area

173 is subjected to increasing fecal contaminations by these different sources leading to the 174 degradation of the quality of oysters. In February, March and August 2013, oysters were 175 sampled at two locations on the bay and analysed for each sampling date.

176

177

178

179

\subsection{Analytical pathways for stanol analysis}

Figure 3 summarizes the different steps involved in the four analytical pathways investigated for the analysis of fecal stanols in oyster tissues. Each step is described in detail below. Briefly, the method 1 consisted of an extraction of lipids with DCM followed by a purification step on silica gel and analysis of fecal stanols by GC-MS. The method 2 consisted of a first purification step of samples with water prior to lipid extraction followed by a purification on silica gel and GC-MS analysis. The method 3 involved a second purification step on aminopropyl-bonded silica gel prior to GC-MS analysis.

\subsubsection{Lipid extraction}

For the three analytical pathways, lipids were extracted using an Accelerated Solvent Extractor (ASE 200, Dionex, Courtaboeuf, France) with DCM. For each sample, about 4 g of freeze-dried tissue were extracted 3 times in pre-washed (with DCM) $33 \mathrm{~mL}$ extraction cells. Each extraction consisted in 2 cycles of 5 min at $100^{\circ} \mathrm{C}$ and 100 bar followed by a 40 second flush step and a 30 second purge step. Each extract was then concentrated under reduced pressure and the 3 extracts were pooled. Then, total lipid extracts were dried, weighed and dissolved in $20 \mathrm{~mL}$ of DCM to obtain a concentration of ca. $20 \mathrm{mg} \mathrm{mL}^{-1}$ of lipids compounds and stored at $-20^{\circ} \mathrm{C}$ until fractionation. 
About $10 \mathrm{~g}$ of silica gel was preconditioned with ca. $50 \mathrm{~mL}$ of a mixture of cyclohexane/DCM (2:1, by vol) and loaded into a $35 \mathrm{~mL}$ chromatography column equipped with a glass frit and a pre-washed (with DCM) cotton wool at the bottom. Aliquots of $5 \mathrm{~mL}$ of total lipid extract, corresponding to ca. $100 \mathrm{mg}$, were made up to a final volume of $15 \mathrm{~mL}$ in cyclohexane to obtain of final ratio of cyclohexane/DCM of 2:1 by volume before loading on the silica column. Nonpolar compounds were eluted with $30 \mathrm{~mL}$ of a mixture of cyclohexane/DCM (2:1, by vol) and the stanol-containing polar fraction was eluted with 40 $\mathrm{mL}$ of a mixture of DCM/Methanol (MeOH, 1:1, by vol). On average, this fraction accounted for $70 \%$ of total lipids. For all samples, the elution was completed with pressurized air. For methods 1 and 3, the polar fraction of interest containing stanols was then dried under reduced pressure and weighed for quantification.

\subsubsection{Aqueous extraction}

For the method 2, freeze-dried tissues were extracted with $50 \mathrm{~mL}$ of ultra-pure water to obtain a ratio of $10 \mathrm{~mL}$ per gram of sample, and extractions were performed with stirrers at ambient temperature overnight [39]. Then the separation of the solid residue from the aqueous extract was performed by centrifugation $\left(2 \times 15 \mathrm{~min}\right.$ at $3500 \mathrm{rpm}$ and $10^{\circ} \mathrm{C}$, Rotenta $460 \mathrm{R}$ centrifuge, Hettich, Tuttlingen, Germany). The solid residue was freeze-dried prior to lipid extraction and the aqueous extract filtered through a $0.7 \mu \mathrm{m}$ glass-fiber filter. In order to analyse the amount of fecal stanols removed from the sample by the water purification step, solid phase extractions were performed on aqueous extracts as described by Jeanneau et al. [39]. 
For method 3, the polar fraction eluted on the silica gel column was loaded on a chromatography column containing about $10 \mathrm{~g}$ of aminopropyl-bonded silica gel $\left(\mathrm{NH}_{2}\right)$ preconditioned with ca. $50 \mathrm{~mL}$ of a mixture of $\mathrm{DCM} / \mathrm{MeOH}$ (1:1, by vol). The fraction containing stanols was eluted with $30 \mathrm{~mL}$ of a mixture of $\mathrm{DCM} / \mathrm{MeOH}$ (1:1, by vol), dried under reduced pressure and weighted for quantification.

\subsubsection{Stanols analysis by gas chromatography-mass spectrometry (GC-MS)}

Stanols were derivatizated using a mixture of BSTFA + TMCS (99:1, by vol) at $60^{\circ} \mathrm{C}$ during 20 minutes to convert hydroxyl groups into trimethylsilyl ether groups.

Stanols as trimethylsilyl ethers were analysed by GC-MS with a Shimadzu QP2010 + MS gas chromatograph/mass spectrometer (Shimadzu, Tokyo, Japan). $1 \mu \mathrm{L}$ of samples was injected in splitless mode at $310^{\circ} \mathrm{C}$. The temperature of the ionization source was set at $200^{\circ} \mathrm{C}$. The temperature of the transfer line was set at $250^{\circ} \mathrm{C}$, and molecules were ionized by electron impact using an energy of $70 \mathrm{eV}$. Separation was achieved using a fused silica column coated with SLB-5 MS (Supelco, $60 \mathrm{~m}$, i.d. $0.25 \mathrm{~mm}$, film thickness $0.25 \mu \mathrm{m}$ ) with helium as carrier gas at a flow of $1 \mathrm{~mL} \mathrm{~min}^{-1}$. The GC oven temperature was maintained at $70^{\circ} \mathrm{C}$ for $1 \mathrm{~min}$, then increased to $130^{\circ} \mathrm{C}$ at $15^{\circ} \mathrm{C} \min ^{-1}$, then to $300^{\circ} \mathrm{C}$ at $3^{\circ} \mathrm{C} \min ^{-1}$ and held at this temperature for $15 \mathrm{~min}$.

Identification of stanols was based on the comparison with mass spectra and retention times of standards. Analyses were performed in selective ion monitoring mode, the identified and quantified stanols were coprostanol, cholestanol, campestanol, stigmastanol, 5 $\beta$ stigmastanol, sitostanol, 24-ethylcoprostanol and 24-ethylepicoprostanol and (Table 1 and 2). Figure 2 presents the structures of coprostanol, sitostanol and other stanols involved in this study. As 24-ethylcoprostanol eluted with other compounds, the mass fragmentogram of this 
signal (main fragments m/z: 253, 296, 343, 386, 470) was a combination of the mass fragmentogram of those coeluted compounds. Therefore, the 215 fragment used to quantify stanols could originate from another compound and was not used here. As the 398 fragment is used as an identification fragment for 24-ethylcoprostanol and as its intensity was similar to as follows: that of the 215 fragment for all calibration solutions, it has been used here as the quantification fragment.

Quantification was based on the internal standard $5 \alpha$-cholestane, which was added to samples after extraction and fractionation steps and prior to derivatization [12, 14, 15, 22, 39] In opposition to recovery standards spiked in oysters (coprostanol and sitostanol) that were used to quantify the efficiency of extraction procedures and to evaluate matrix effects, the internal standard was used to evaluate losses of sensivity of the detection with GC-MS. The quantification method used a five-point calibration curve (standards: coprostanol, cholestanol and sitostanol) at concentrations of $1,3,5,8$, and $10 \mu \mathrm{g} \mathrm{mL}^{-1}$ with a constant internal standard concentration of $5 \mu \mathrm{g} \mathrm{mL} \mathrm{m}^{-1}$. Considering the mass of samples and dilutions performed during the analytical procedures, the limits of quantification for stanols analysed in oysters ranged from 5 to $50 \mu \mathrm{g} \mathrm{g}^{-1} \mathrm{DW}$. Linearity of calibration curves, detection limits of GC-MS and fragment used for the quantification of stanols are described in the Table 1.

The recoveries of spiked coprostanol and sitostanol (recovery standards) were calculated 
In order to investigate the level of fecal contamination of oysters from the Fresnaye bay, the concentration of the fecal indicator bacteria Escherichia coli was determined by IFREMER (Laboratoire National de Référence , Nantes, France) using the impedance method [41].

\subsection{Statistical analyses}

The analyses were conducted on three replicates for each sample for the comparison of the efficiencies of the three analytical pathways on the recoveries of both recovery standards and on two replicates for oysters from the Fresnaye bay. As non-parametric tests can lead to the conclusion that observed differences are not significant whereas qualitative differences are evident for low replication, comparison of stanol concentrations between samples were only qualitative.

Stanol fingerprints of oysters from the Fresnaye bay were investigated using the principal component analysis (PCA) model set up by Derrien et al. [22] with XLSTAT 2013 (Addinsoft, Paris, France). Briefly, this model is based on the distribution of six main fecal stanols (i.e., coprostanol, epicoprostanol, 24-ethylcoprostanol, 24 ethylepicoprostanol, campestanol, and sitostanol) of 88 various samples from bovine, porcine (faeces, manures, slurries...) and human origin (raw and diluted waste water treatment plant effluent, sewage sludges). The PCA plot is a two-dimensional graphic representation of the correlations between the 6 stanols (variables). This plan is built on two axis (principal components) F1 and F2, which explain $78.3 \%$ of the total variance of the model. Each of the 6 stanol distribution contributes to F1 and F2 axis. This model distinguish the stanol fingerprints from the three previous origins into three distinctive clusters. Based, on their abundance of the 6 previous stanols, the coordinates of samples on the PCA plots are calculated as follows: 
- $\mathrm{F} 1$ coordonate $=0.497(\%$ coprostanol $)-0.347(\%$ epicoprostanol $)+$

0.295(\%ethylepicoprostanol) - 0.460 (\%ethylepicoprostanol) - 0.422 (\%sitostanol) -

292

293

294

295

296

297

298

299

300

301

302

303

304

305

306

307

308

309

310

311

312

313

0.395(\%campestanol)

- F2 coordonate $=-0.074(\%$ coprostanol $)+0.565(\%$ epicoprostanol $)+$ 0.531(\%ethylcoprostanol) $\quad-\quad 0.303$ (\%ethylepicoprostanol) $\quad-\quad 0.288(\%$ sitostanol) + 0.468(\%campestanol).

These equations allow the identification of the origin of fecal contamination in environmental matrix between, bovine, porcine and human contaminations using this PCA model.

\section{Results and Discussion}

3.1. Method comparison

\subsubsection{Water extraction}

Non-lipid compounds can interact with lipids and decrease the efficiency of their extraction from the sample matrix or their separation during solid-phase chromatography. Thus, the addition of an extraction step with water is expected to increase the recovery of target lipids. To investigate the effects of water extractions on the recovery of coprostanol and sitostanol in oysters, we compared the method 1 (organic extraction and silica gel purification) to the method 2 (water extraction, organic extraction and silica gel purification).

Figure 4 presents recoveries of both coprostanol and sitostanol for the two methods tested.

The recovery of coprostanol extracted with the method 2 (59 $\pm 10 \%$, mean \pm standard deviation, SD) was lower than that extracted with the method 1 (79 $\pm 8 \%$ ) and the two methods led to similar repeatabilities. Similarly, the recovery of sitostanol extracted with the 
method 2 (47 $\pm 13 \%$ ) was lower than that extracted with the method 1 (84 $\pm 8 \%$ ) and the repeatability of the method 2 was lower than that of the method 1. Contrary to our hypothesis, the recoveries of both coprostanol and sitostanol extracted with the method 2 tended to be lower than those of the method 1 . This result suggests that the extraction step with water removed more coprostanol and sitostanol than it decreased the potential interactions of these two molecules with non-lipid compounds. Interestingly, the addition of coprostanol and sitostanol quantities analysed in aqueous extracts by solid phase extraction to the quantities of coprostanol and sitostanol in oyster tissues extracted with the method 2 led to quite similar recoveries (61 versus $59 \%$ for coprostanol and 54 versus $47 \%$ for sitostanol) and remained lower than those without the water extraction (method 1). This imbalance could be attributed to the low efficiency of solid phase extraction on aqueous extracts that are very rich in hydrophilic organic compounds, which greatly decrease the efficiency of this method [40]. Unfortunately, the efficiency of solid phase extractions could not be checked because of the coelution of the recovery standard cholesterol $\mathrm{d}_{6}$ with cholesterol.

\subsubsection{Aminopropyl-bonded silica gel $\left(\mathrm{NH}_{2}\right)$ purification}

Oysters contain high amounts of lipids from different classes that can potentially interact each other's and decrease the efficiency of their analysis [32, 33, 37]. The effects of a purification step with $\mathrm{NH}_{2}$ was tested in order to remove as much as compounds of noninterest as possible. The comparison of the efficiency of the methods 1 (organic extraction and silica gel purification) and 3 (organic extraction, silica gel and $\mathrm{NH}_{2}$ purifications) allows the investigation of the impact of this second purification step.

The recoveries of coprostanol were $79 \pm 8 \%$ and $89 \pm 15 \%$ for the methods 1 and 3, respectively and the recoveries of sitostanol were $84 \pm 8 \%, 103 \pm 70 \%$ for the methods 1 and 3, respectively (Figure 4). The addition of this second chromatographic step involving 
aminopropyl-bonded silica seems to induce an increase of the recoveries of both coprostanol and sitostanol. However, the standard deviation between the triplicates highlights that the values of the recoveries belong to the same group and that the methods appear to be not different. The repeatability of the methods 1 and 3 can be inferred from the value of the relative standard deviation. For the method 1 , the relative standard deviation represented 10 and $9 \%$ of the mean value for coprostanol and sitostanol, respectively, while for method 3 it represented 17 and $68 \%$ of the mean value for coprostanol and sitostanol, respectively.

\subsubsection{Comparison of the three methods}

The first goal of the present study was to determine an efficient method for the analysis of fecal stanols in the oyster Crassostrea gigas.

Water extraction led to opposite trends on coprostanol and sitostanol recoveries and increased their respective standard deviation. Thus, the addition of this step on the extraction pathway i) did not increase the recovery of both recovery standards and ii) decreased their repeatabilities. As a consequence, water extraction prior to organic extraction is not reliable for the analysis of fecal stanols in oysters.

The addition of a purification step on $\mathrm{NH}_{2}$ increased the recoveries of coprostanol and sitostanol. Nevertheless, this step strongly decreased the repeatabilities of the methods tested, especially for sitostanol. Therefore, this step does not appear to be reliable for the analysis of fecal stanols in oysters.

Finally, among the three methods tested, , the method 1, which included a lipid extraction step with organic solvent, a purification step on silica gel and analysis by GC-MS, led to i) statistically similar recoveries than the others two methods, ii) the higher repeatability and iii) similar recoveries for both recovery standards. Moreover, the recovery of coprostanol with the 
method 1 (79\%) is higher than that found by Cathum and Sabik [27] (48\%) probably because these authors analysed coprostanol by GC-MS as underivatized compound.

In order to further improvement of this method and solvent and sorbent savings, stanol extraction efficiency could be investigate using pre-packed silica cartridges available for solid-phase extraction.

Finally, the method 1 has been chosen to analyse the concentration of fecal stanols in natural oysters sampled at the Fresnaye bay.

\subsection{Stanol occurrence and concentrations in natural oysters from the Fresnaye bay}

Table 2 presents the concentrations of the stanols quantified in oysters sampled in February, March and August 2013.

Eight stanols were detected and quantified in the samples analysed. Cholestanol was the major compound and ranged from $58.4 \mu \mathrm{g} \mathrm{g}^{-1} \mathrm{DW}$ (August) to $221.8 \mu \mathrm{g} \mathrm{g}^{-1} \mathrm{DW}$ (February). As these concentrations were above the upper limit of quantification of our method (i.e. $50 \mu \mathrm{g}$ $\left.\mathrm{g}^{-1} \mathrm{DW}\right)$, they were just qualitatively discussed in comparison to the concentrations of the other stanol found in oysters. The other stanols detected and quantified were coprostanol, $5 \beta$ stigmastanol, 24-ethylcoprostanol, 24-ethylepicoprostanol, campestanol, stigmastanol and sitostanol and their concentrations ranged from 7.5 to $21.7 \mu \mathrm{g} \mathrm{g}^{-1} \mathrm{DW}$. The predominance in Crassostrea gigas of cholestanol compared to other stanols is not surprising since its precursor, cholesterol, is the main sterol in oysters [42-44]. Dunstan et al. [43] found concentration of cholestanol of ca. $112 \mu \mathrm{g} \mathrm{g}^{-1} \mathrm{DW}$ for Crassostrea gigas that is our range of concentrations for cholestanol. Since cholestanol have been rarely found or in very low concentrations in the diet of bivalves largely dominated by phytoplankton [45, 46], its high relative abundance in bivalves might be due to the bioconversion of cholesterol during the digestive process by the presence of gut bacteria [47]. However, cholesterol might not be the 
only dietary sterol supplied by food leading to the formation of cholestanol within bivalves. Indeed, it has been shown that marine bivalves are able to bioconvert several dietary sterols into cholesterol for physiological needs [43, 48]. Furthermore, the high variability of cholestanol concentrations between oyster samples from date to date are accompanied by high variations of total stanol concentrations, which ranged from $145.0 \mu \mathrm{g} \mathrm{g}^{-1} \mathrm{DW}$ (August) to $297.6 \mu \mathrm{g} \mathrm{g}^{-1} \mathrm{DW}$ (February). These variations might be due to the differences in physicochemical conditions of surrounding seawater between sampling dates that could have led to different metabolic responses of oysters resulting in different stanol concentrations.

\subsection{Fecal contamination and stanol fingerprint of oysters}

The concentration of Escherichia coli in oysters sampled in February and March was respectively 67 and 220 Most Probable Number $100 \mathrm{~g}^{-1}$ (Table 2). According to the European Shellfish Directive on shellfish harvesting (854/2004/EC), these amounts of Escherichia coli classified the two previous samples in the A class and oysters collected in February and March were considered as non-fecally contaminated. With a concentration of Escherichia coli of ca. 9150 Most Probable Number $100 \mathrm{~g}^{-1}$, oysters sampled in August were classified in the B class and considered here as fecally contaminated.

In order to investigate the ability of oysters to record a species-specific fecal contamination by bioaccumulation using their stanol fingerprint, the relative proportions of fecal stanols of the three samples were injected in the PCA developed by Derrien et al. [14]. Stanol fingerprints of oysters sampled in February (F1 and F2) and March (M1 and M2) were located between the bovine and the human clusters (Figure 5). This absence of a specific fingerprint is consistent with the absence of a fecal contamination of these samples measured with Escherichia coli. By contrast, the fecally contaminated oysters sampled in August (A1 and A2) showed specific stanol fingerprints located in the bovine cluster (Figure 5). The 
absence of a specific stanol fingerprint of oysters when they are not fecally contaminated in addition to the specific stanol fingerprint of oysters fecally contaminated suggests that these organisms could be able to record a species-specific stanol fingerprint when they are exposed to a fecal contamination high enough. The bovine fingerprint of oysters sampled in August suggests that the fecal contaminations transferred from the watershed to seawater and bioaccumulated by oysters during this period would mainly originate from bovine sources. This hypothesis is consistent with the agricultural activity of the watershed where livestock farming of cows is not negligible with ca. 5300 heads of livestock in 2010 [38]. The contamination of oysters by bovine sources suggested by their specific stanol fingerprint in August could be explained by agricultural practices and manure spreading calendar. Indeed, during summer, cows are grazing on grassland and thought lixiviation and erosion of soils during raining events, even low, their faeces can be directly transported to streams that flow into the bay. In August, pig slurry spreading is forbidden, so the large quantities of pig slurry produced by pig farming (ca. 235.000 pigs in 2010 in the watershed) remain stored, limiting the fecal contamination of soils, streams and finally shellfish by this source.

In conclusion, the method developed here enables to analyse the concentration of eight fecal stanols in oysters and to record and identify the main source of fecal contamination of oysters using their stanol fingerprint with PCA. Stanol fingerprint could then be used as a microbial source tracking tool in oysters to track the origin of the fecal contamination in shellfish in order to enhance watershed management and reduce health risks linked to the consumption of contaminated shellfish.

\section{Acknowledgements}

As a part of the Riskmanche project (http://www.brighton.ac.uk/riskmanche/), this study was fully funded by the Interreg IV A France (Channel) - England cross-border European 
438 cooperation programme. We thank the Laboratoire National de Référence for analyses of 439 Escherichia coli, Mr. Pascal Blanchard for oyster supply, colleagues from the Laboratoire 440 Santé Environnement et Microbiologie (IFREMER, Plouzané, France) for oyster sampling 441 and Dr. Justine Jaguin for her graphical help. 


\section{References}

445

1. Fong T-T, Lipp EK (2005) Enteric viruses of humans and animals in aquatic environments: health risks, detection, and potential water quality assessment tools. Microbiol Mol Biol Rev 69:357-71. doi: 10.1128/MMBR.69.2.357-371.2005

2. Hundesa A, Maluquer de Motes C, Bofill-Mas S, et al. (2006) Identification of human and animal adenoviruses and polyomaviruses for determination of sources of fecal contamination in the environment. Appl Environ Microbiol 72:7886-93. doi: 10.1128/AEM.01090-06

3. Soller J, Embrey M, Tuhela L, et al. (2010) Risk-based evaluation of Escherichia coli monitoring data from undisinfected drinking water. J Environ Manage 91:2329-35. doi: 10.1016/j.jenvman.2010.06.017

4. Zatta P, Gobbo S, Rocco P, et al. (1992) Evaluation of heavy metal pollution in the Venetian lagoon by using Mytilus galloprovincialis as biological indicator. Sci Total Environ 119:29-41. doi: 10.1016/0048-9697(92)90253-O

5. Baudrimont M, Schäfer J, Marie V, et al. (2005) Geochemical survey and metal bioaccumulation of three bivalve species (Crassostrea gigas, Cerastoderma edule and Ruditapes philippinarum) in the Nord Médoc salt marshes (Gironde estuary, France). Sci Total Environ 337:265-280.

6. Goulletquer P, Le Moine O (2002) Shellfish farming and coastal zone management (CZM) development in the Marennes-Oleron Bay and Charentais Sounds (Charente Maritime, France): A review of recent developments. Aquac Int 10:507-525. doi: 10.1023/A:1023975418669 
7. Mieszkin S, Caprais MP, Le Mennec C, et al. (2013) Identification of the origin of fecal contamination in estuarine oysters using Bacteroidales and F-specific RNA bacteriophage markers. J Appl Microbiol 115:897-907. doi: 10.1111/jam.12260

8. Simpson JM, Santo Domingo JW, Reasoner DJ (2002) Microbial Source Tracking: State of the Science. Environ Sci Technol 36:5279-5288. doi: 10.1021/es026000b

9. Glassmeyer ST, Furlong ET, Kolpin DW, et al. (2005) Transport of Chemical and Microbial Compounds from Known Wastewater Discharges: Potential for Use as Indicators of Human Fecal Contamination. Environ Sci Technol 39:5157-5169. doi: 10.1021/es048120k

10. Cimenti M, Hubberstey A, Bewtra J, Biswas N (2007) Alternative methods in tracking sources of microbial contamination in waters. Water SA 33:183-194.

11. Field KG, Samadpour M (2007) Fecal source tracking, the indicator paradigm, and managing water quality. Water Res 41:3517-38. doi: 10.1016/j.watres.2007.06.056

12. Jardé E, Gruau G, Mansuy-Huault L, et al. (2006) Using Sterols to Detect Pig Slurry Contribution to Soil Organic Matter. Water Air Soil Pollut 178:169-178. doi: 10.1007/s11270-006-9188-9

13. Ahmad F, Tourlousse DM, Stedtfeld RD, et al. (2009) Detection and Occurence of Indicator Organisms and Pathogens. Water Environ Res 81:959-980. doi: $10.2175 / 106143009 X 12445568399299$

14. Derrien M, Jardé E, Gruau G, et al. (2012) Origin of fecal contamination in waters from contrasted areas: stanols as Microbial Source Tracking markers. Water Res 46:4009-16. doi: 10.1016/j.watres.2012.05.003

15. Biache C, Philp RP (2013) The use of sterol distributions combined with compound specific isotope analyses as a tool to identify the origin of fecal contamination in rivers. Water Res 47:1201-8. doi: 10.1016/j.watres.2012.11.037 
16. Chan K-H, Lam MHW, Poon K-F, et al. (1998) Application of sedimentary fecal stanols and sterols in tracing sewage pollution in coastal waters. Water Res 32:225235. doi: 10.1016/S0043-1354(97)00175-9

17. Leeming R, Ball A, Ashbolt N, Nichols P (1996) Using fecal sterols from humans and animals to distinguish fecal pollution in receiving waters. Water Res 30:2893-2900. doi: 10.1016/S0043-1354(96)00011-5

18. Bull ID, Lockheart MJ, Elhmmali MM, et al. (2002) The origin of faeces by means of biomarker detection. Environ Int 27:647-654. doi: 10.1016/S0160-4120(01)00124-6

19. Tyagi P, Edwards DR, Coyne MS (2009) Distinguishing between human and animal sources of fecal pollution in waters: a review. Int $\mathrm{J}$ Water 5:15. doi: 10.1504/IJW.2009.023080

20. Gourmelon M, Caprais MP, Le Mennec C, et al. (2010) Application of libraryindependent microbial source tracking methods for identifying the sources of fecal contamination in coastal areas. Water Sci Technol 61:1401. doi: 10.2166/wst.2010.033

21. Shah VG, Dunstan RH, Geary PM, et al. (2007) Evaluating potential applications of fecal sterols in distinguishing sources of fecal contamination from mixed fecal samples. Water Res 41:3691-700. doi: 10.1016/j.watres.2007.04.006

22. Derrien M, Jarde E, Gruau G, Pierson-Wickmann A-C (2011) Extreme variability of steroid profiles in cow feces and pig slurries at the regional scale: implications for the use of steroids to specify fecal pollution sources in waters. J Agric Food Chem 59:7294-302. doi: 10.1021/jf201040v

23. Water National Agency of Loire-Brittany. (accessed Jan. 2014). http://www.eau-loirebretagne.fr/informations_et_donnees/reseaux_de_mesure 
24. Solecki O, Jeanneau L, Jardé E, et al. (2011) Persistence of microbial and chemical pig manure markers as compared to fecal indicator bacteria survival in freshwater and seawater microcosms. Water Res 45:4623-33. doi: 10.1016/j.watres.2011.06.012

25. Jeanneau L, Solecki O, Wéry N, et al. (2012) Relative decay of fecal indicator bacteria and human-associated markers: a microcosm study simulating wastewater input into seawater and freshwater. Environ Sci Technol 46:2375-82. doi: 10.1021/es203019y

26. Sherwin MR, Van Vleet ES, Fossato VU, Dolci F (1993) Coprostanol (5ß-cholestan$3 \beta-o l)$ in lagoonal sediments and mussels of Venice, Italy. Mar Pollut Bull 26:501507. doi: 10.1016/0025-326X(93)90467-X

27. Cathum S, Sabik H (2001) Determination of steroids and coprostanol in surface water, effluent and mussel using gas chromatography-mass spectrometry. Chromatographia 53:S394-S399. doi: 10.1007/BF02490364

28. Gagné F, Blaise C, Aoyama I, et al. (2002) Biomarker study of a municipal effluent dispersion plume in two species of freshwater mussels. Environ Toxicol 17:149-59. doi: 10.1002/tox.10046

29. Gagné F, Blaise C, Lachance B, et al. (2001) Evidence of coprostanol estrogenicity to the freshwater mussel Elliptio complanata. Environ Pollut 115:97-106. doi: 10.1016/S0269-7491(01)00089-6

30. Hellou J, Yeats P, Steller S, Gagné F (2003) Chemical contaminants and biological indicators of mussel health during gametogenesis. Environ Toxicol Chem 22:2080. doi: 10.1897/02-396

31. Yeats P, Gagné F, Hellou J (2008) Body burden of contaminants and biological effects in mussels: an integrated approach. Environ Int 34:254-64. doi: 10.1016/j.envint.2007.08.009 
32. Linehan L., O’Connor T., Burnell G (1999) Seasonal variation in the chemical composition and fatty acid profile of Pacific oysters (Crassostrea gigas). Food Chem 64:211-214. doi: 10.1016/S0308-8146(98)00144-7

33. Costil K, Royer J, Ropert M, et al. (2005) Spatio-temporal variations in biological performances and summer mortality of the Pacific oyster Crassostrea gigas in Normandy (France). Helgol Mar Res 59:286-300. doi: 10.1007/s10152-005-0004-5

34. Danger M, Allard B, Arnous M, et al. (2012) Effects of food-web structure on the quantity and the elemental quality of sedimenting material in shallow lakes. Hydrobiologia 679:251-266. doi: 10.1007/s10750-011-0890-2

35. Guenet B, Danger M, Harrault L, et al. (2014) Fast mineralization of land-born C in inland waters: first experimental evidences of aquatic priming effect. Hydrobiologia 721:35-44. doi: 10.1007/s10750-013-1635-1

36. Lacaze J-PCL, Stobo LA, Turrell EA, Quilliam MA (2007) Solid-phase extraction and liquid chromatography--mass spectrometry for the determination of free fatty acids in shellfish. J Chromatogr A 1145:51-7. doi: 10.1016/j.chroma.2007.01.053

37. Pernet F, Pelletier CJ, Milley J (2006) Comparison of three solid-phase extraction methods for fatty acid analysis of lipid fractions in tissues of marine bivalves. $\mathrm{J}$ Chromatogr A 1137:127-37. doi: 10.1016/j.chroma.2006.10.059

38. French Ministry of Agriculture, Agri-food and Forests (accessed Jan. 2014). http://www.acces.agriculture.gouv.fr/cartostat/\#v=map2;i=stru1.saumoy10;l=fr

39. Jeanneau L, Jardé E, Gruau G (2011) Influence of salinity and natural organic matter on the solid phase extraction of sterols and stanols: application to the determination of the human sterol fingerprint in aqueous matrices. J Chromatogr A 1218:2513-20. doi: 10.1016/j.chroma.2011.02.066 
40. Landgraf D, Leinweber P, Makeschin F (2006) Cold and hot water-extractable organic matter as indicators of litter decomposition in forest soils. J plant Nutr ans soil Sci 169:76-82. doi: 10.1002/jpin.200521711

41. Dupont J, Dumont F, Menanteau C, Pommepuy M (2004) Calibration of the impedance method for rapid quantitative estimation of Escherichia coli in live marine bivalve molluscs. J Appl Microbiol 96:894-902. doi: 10.1111/j.13652672.2004.02218.x

42. Gordon DT, Collins N (1982) Anatomical distribution of sterols in oysters (Crassostrea gigas). Lipids 17:811-817. doi: 10.1007/BF02535358

43. Dunstan GA, Volkman JK, Barrett SM (1993) The effect of lyophilization on the solvent extraction of lipid classes, fatty acids and sterols from the oysterCrassostrea gigas. Lipids 28:937-944. doi: 10.1007/BF02537504

44. Knauer J, Kerr RG, Lindley D, Southgate PC (1998) Sterol Metabolism of Pacific Oyster (Crassostrea gigas) Spat. Comp Biochem Physiol Part B Biochem Mol Biol 119:81-84. doi: 10.1016/S0305-0491(97)00269-1

45. Nishimura M, Koyama T (1977) The occurrence of stanols in various living organisms and the behavior of sterols in contemporary sediments. Geochim Cosmochim Acta 41:379-385. doi: 10.1016/0016-7037(77)90265-4

46. Volkman JK (2003) Sterols in microorganisms. Appl Microbiol Biotechnol 60:495506. doi: 10.1007/s00253-002-1172-8

47. Harris JM (1993) The presence, nature, and role of gut microflora in aquatic invertebrates - a synthesis. Microb Ecol 25:195-231.

48. Berenberg CJ, Patterson GW (1981) The relationship between dietary phytosterols and the sterols of wild and cultivated oysters. Lipids 16:276-278. doi: 10.1007/BF02535028 
589

590

591

592

593

594

595

596

597

598

599

600

601

602

603

604

605

606

607

608

609

610

Figure legends:

Figure 1: Location of oyster sampling sites, streams, towns and waste water treatment plants (WWTP) in the Fresnaye watershed, Brittany, France.

Figure 2: Generalized structure of a stanol. The distinction between main fecal stanols involves four points: i) the orientation ( $\alpha$ or $\beta$ ) of the hydrogen atom at the position $\mathrm{C}-5$ (mediated by the anaerobic reduction of the double bond located at the same position in the corresponding unsaturated sterol precursor), ii) the orientation ( $\alpha$ or $\beta$ ) of the hydroxyl group at the position C-3, iii) the occurrence of methyl or ethyl groups at position C-24 (denoted by $\mathrm{R})$, and iv) the occurrence of a double bond at position C-22.

Figure 3: Schematic representation of the three analytical pathways used for the extraction and the purification of fecal stanols from oyster samples (blanks and spiked ones) and their subsequent analysis by GC-MS.

Figure 4: Comparison of coprostanol and sitostanol recoveries in oysters for the three extraction methods. Error bars are standard deviations $(n=3)$. Values under the error bars are relative standard deviations. The dotted line represents the $100 \%$ recovery threshold.

Figure 5: Plot of the principal component analysis comparing the 88 source samples and the 6 oyster samples using the 6 most discriminant stanol compounds proposed by Derrien et al. 
611 (2012). Each source samples was used as individual and oyster samples were used as

612 supplementary individuals. F1 axis: principal component 1; F2 axis: principal component 2. 
Figure 1:

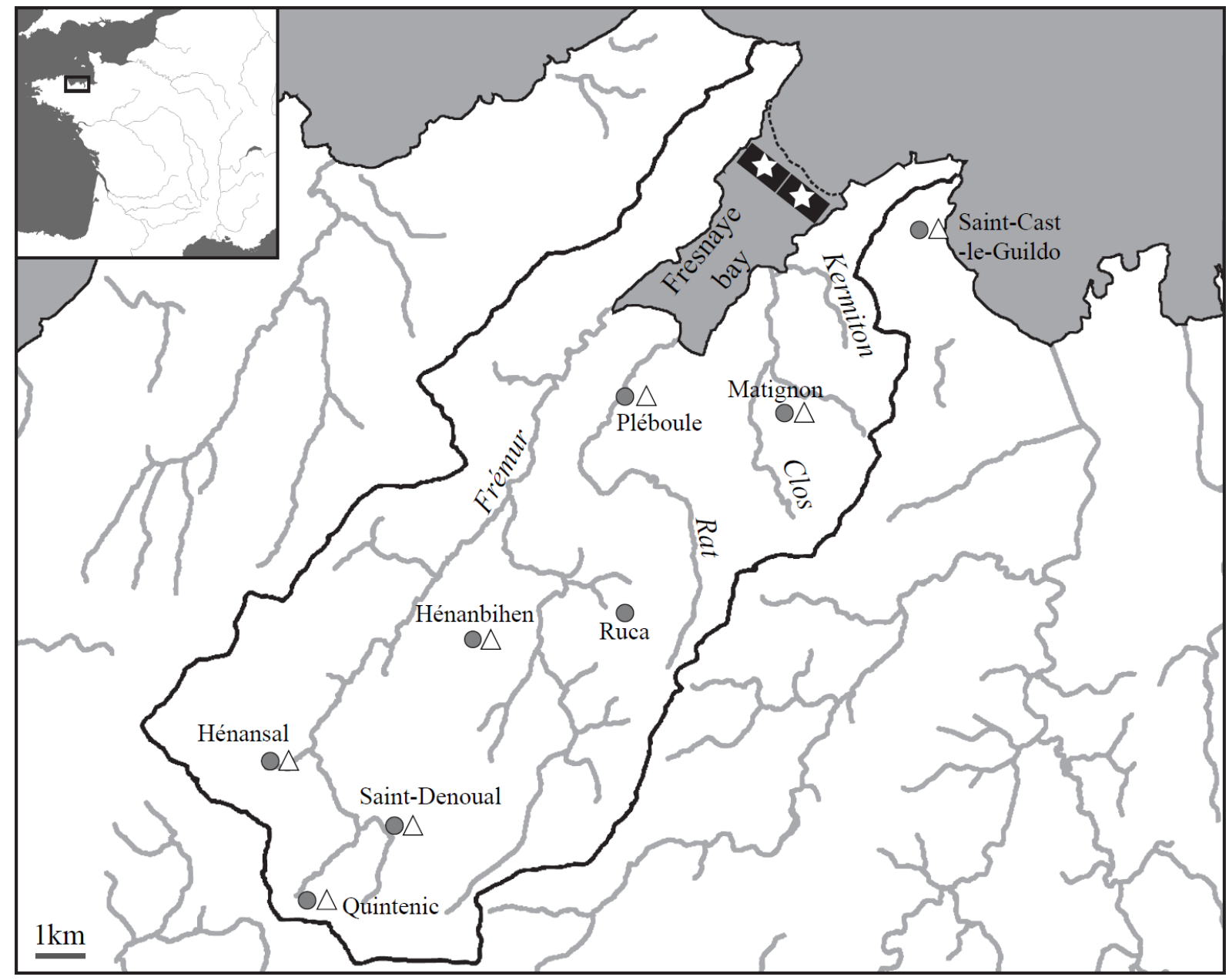

O Towns $\triangle$ WWTP Stream $\measuredangle$ Watershed boundaries $\lesssim$ Sampling site 
Figure 2 :

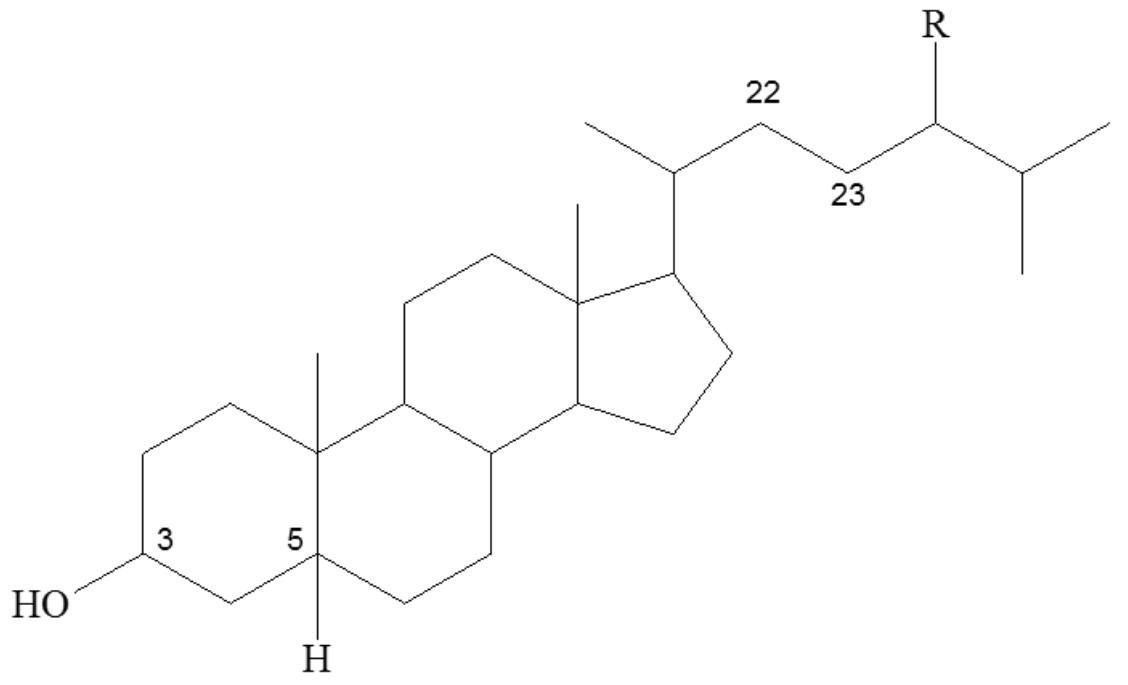

\begin{tabular}{|c|c|c|c|}
\hline $\begin{array}{l}\mathrm{R}=\mathrm{H} \\
3 \mathrm{C}-\mathrm{OH}=\beta \\
5 \mathrm{C}-\mathrm{H}=\beta\end{array}$ & Coprostanol & $\begin{array}{l}\mathrm{R}=\mathrm{C}_{2} \mathrm{H}_{5} \\
3 \mathrm{C}-\mathrm{OH}=\beta \\
5 \mathrm{C}-\mathrm{H}=\beta\end{array}$ & 24-Ethylcoprostanol \\
\hline $\begin{array}{l}\mathrm{R}=\mathrm{H} \\
3 \mathrm{C}-\mathrm{OH}=\beta \\
5 \mathrm{C}-\mathrm{H}=\alpha\end{array}$ & Cholestanol & $\begin{array}{l}\mathrm{R}=\mathrm{C}_{2} \mathrm{H}_{5} \\
3 \mathrm{C}-\mathrm{OH}=\alpha \\
5 \mathrm{C}-\mathrm{H}=\beta\end{array}$ & 24-Ethylepicoprostanol \\
\hline $\begin{array}{l}\mathrm{R}=\mathrm{CH}_{3} \\
3 \mathrm{C}-\mathrm{OH}=\beta \\
5 \mathrm{C}-\mathrm{H}=\alpha\end{array}$ & Campestanol & $\begin{array}{l}\mathrm{R}=\mathrm{C}_{2} \mathrm{H}_{5} \\
3 \mathrm{C}-\mathrm{OH}=\beta \\
5 \mathrm{C}-\mathrm{H}=\alpha\end{array}$ & $\underline{\text { Sitostanol }}$ \\
\hline $\begin{array}{l}\mathrm{R}=\mathrm{C}_{2} \mathrm{H}_{5} \\
3 \mathrm{C}-\mathrm{OH}=\beta \\
5 \mathrm{C}-\mathrm{H}=\alpha \\
22 \mathrm{C}-23 \mathrm{C}=\end{array}$ & $\underline{\text { Stigmastanol }}$ & $\begin{array}{l}\mathrm{R}=\mathrm{C}_{2} \mathrm{H}_{5} \\
3 \mathrm{C}-\mathrm{OH}=\beta \\
5 \mathrm{C}-\mathrm{H}=\beta \\
22 \mathrm{C}-23 \mathrm{C}=\end{array}$ & $\underline{5 \beta \text {-Stigmastanol }}$ \\
\hline
\end{tabular}


Figure 3 :

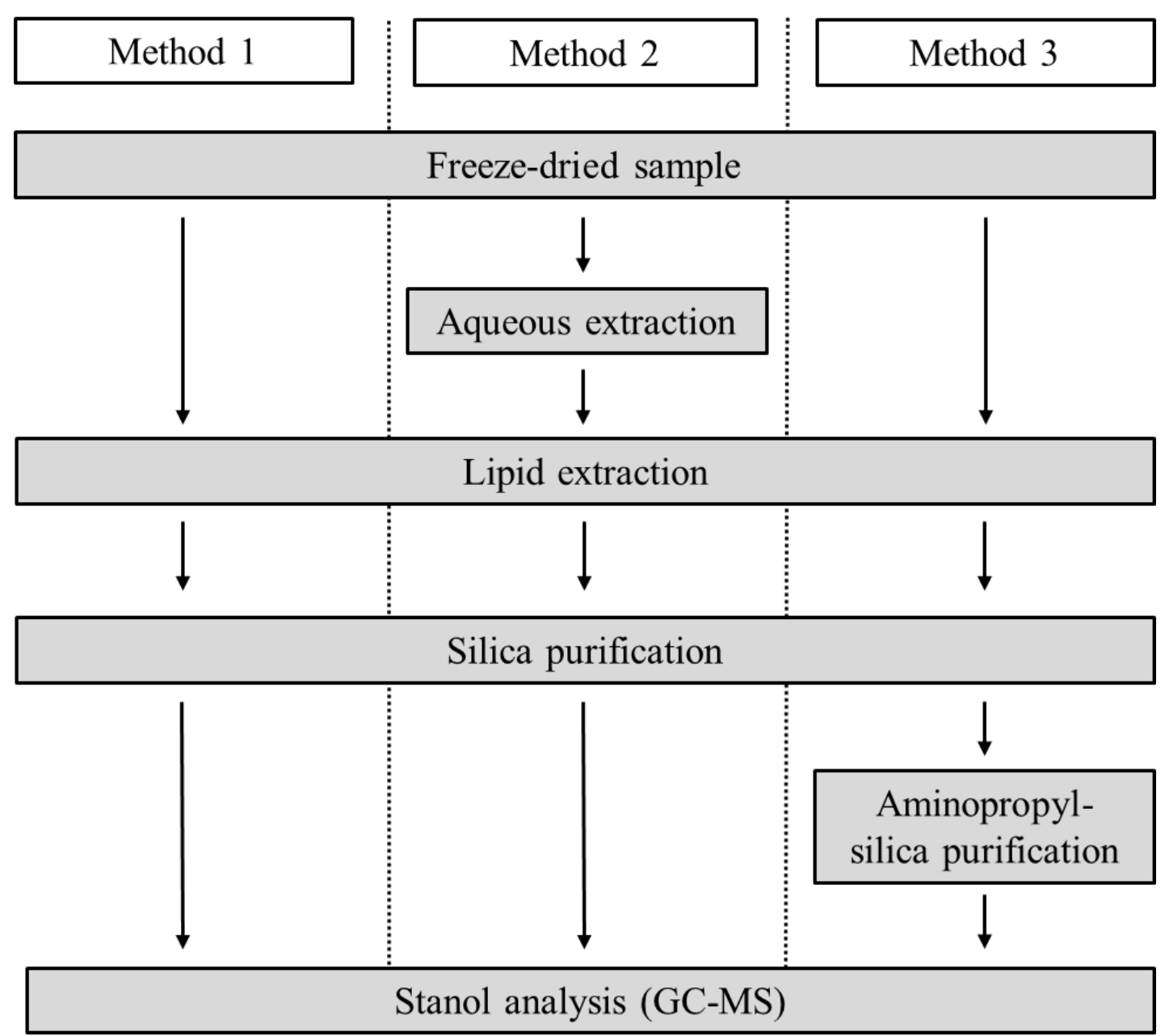


Figure 4 :

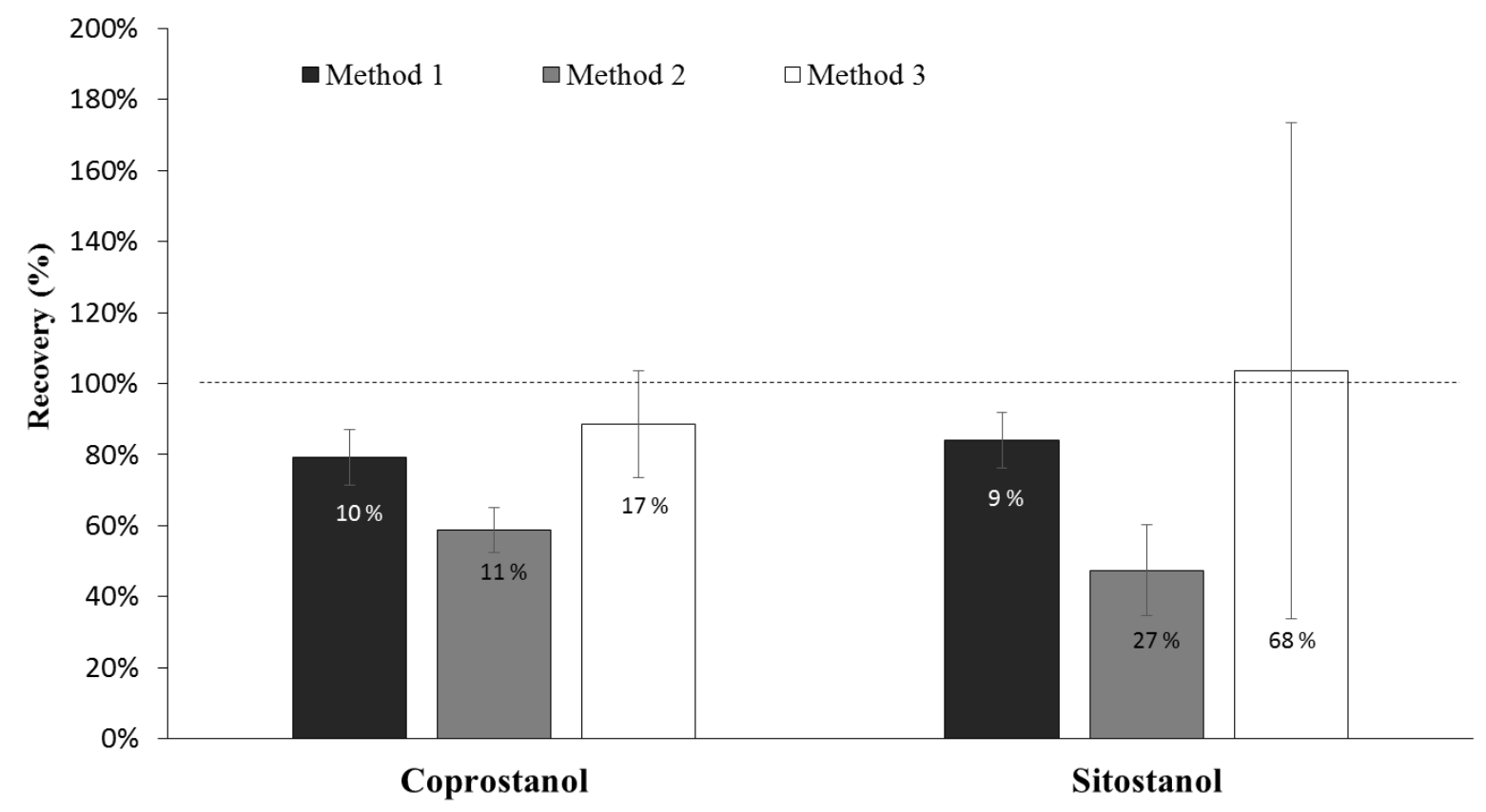


Figure 5 :

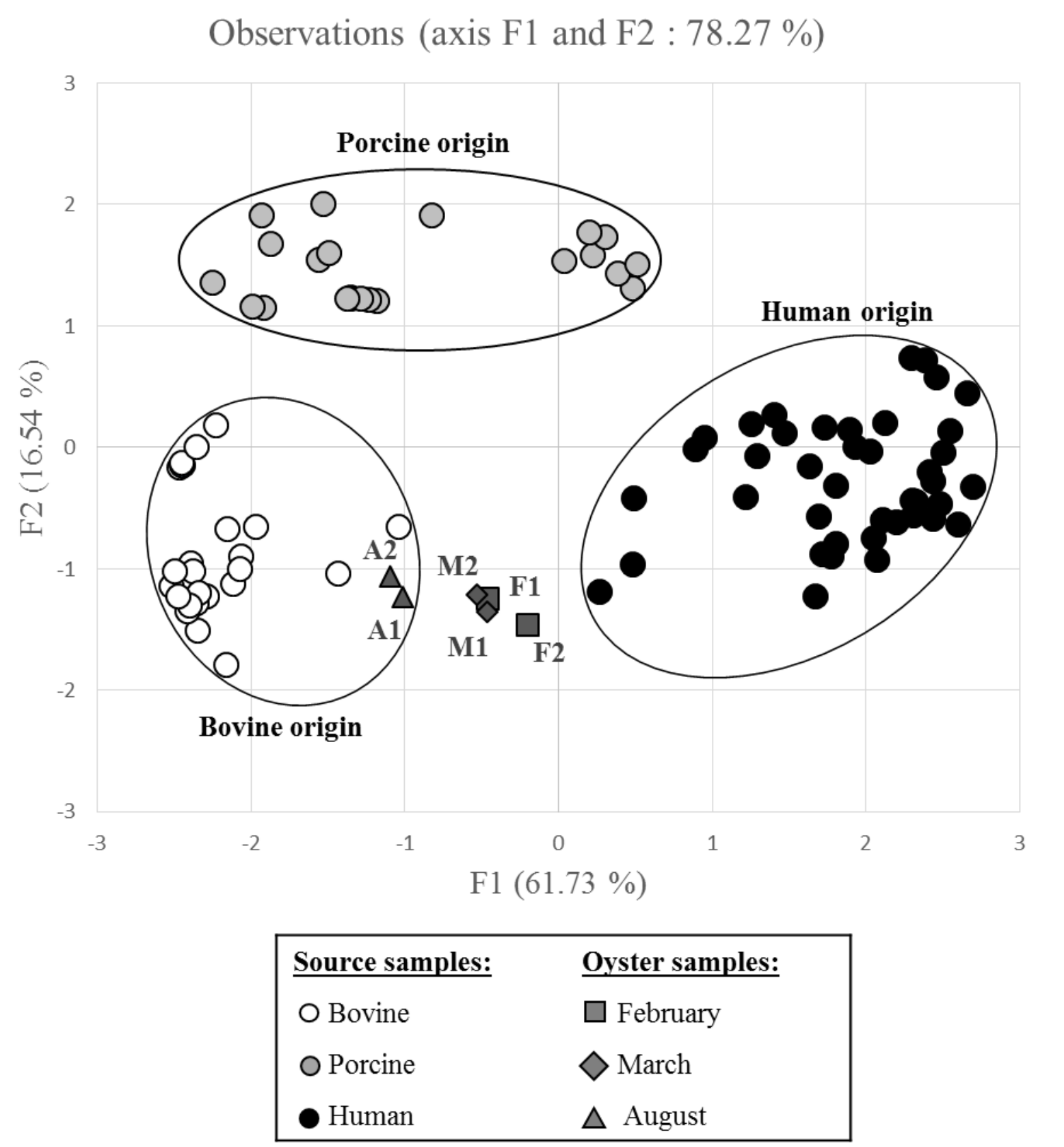


Table 1: Trivial and IUPAC names, retention times relative to cholestanol (RRT), $\mathrm{m} / \mathrm{z}$ values used for the identification and quantification of stanols, and information on quantification compounds (standard used, linearity of the corresponding calibration curve, and limit of detection).

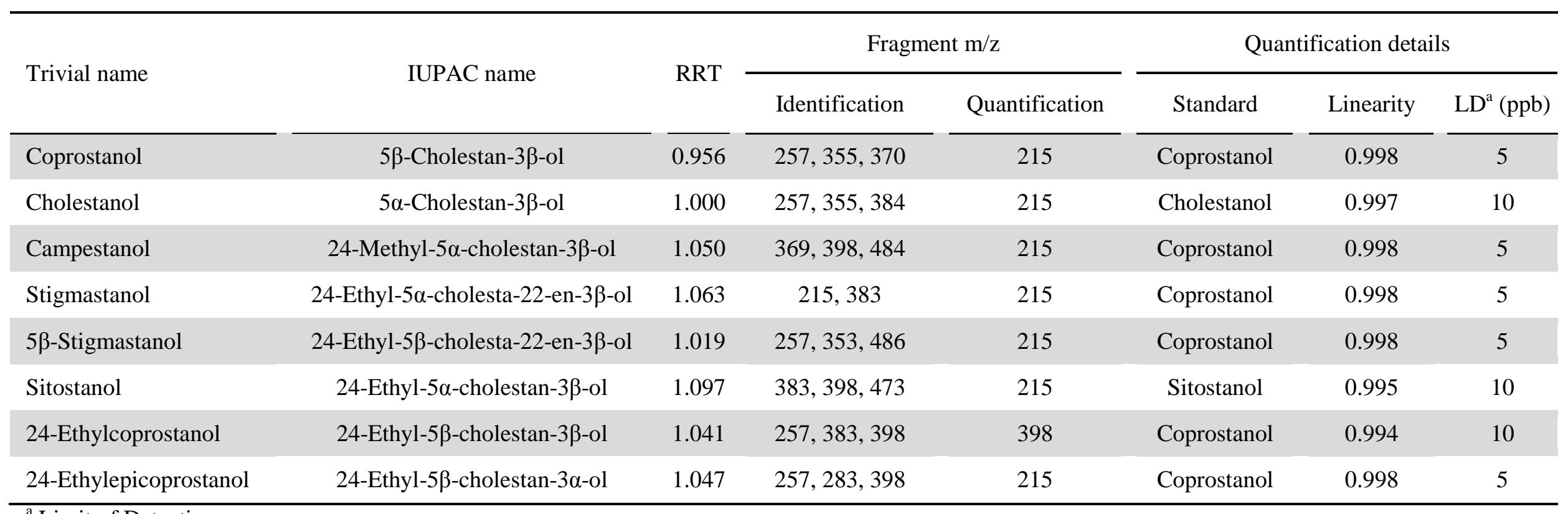

${ }^{\mathrm{a}}$ Limit of Detection 
Table 2 : Stanol ( $\mu \mathrm{g} \mathrm{g}^{-1} \mathrm{DW}$ ) and Escherichia coli (Most Probable Number $100 \mathrm{~g}^{-1}$ of meat and shell liquor) concentrations of oysters from the Fresnaye bay. Errors are standard deviations $(n=2)$.

\begin{tabular}{|c|c|c|c|}
\hline \multirow{2}{*}{ Concentration } & \multicolumn{3}{|c|}{ Sampling date } \\
\hline & February & March & August \\
\hline Coprostanol & $7.9 \pm 1.4$ & $7.4 \pm 0.1$ & $10.4 \pm 1.2$ \\
\hline Cholestanol & $221.8 \pm 83.0$ & $110.3 \pm 16.3$ & $58.4 \pm 12.0$ \\
\hline Campestanol & $16.1 \pm 0.7$ & $10.8 \pm 0.2$ & $12.2 \pm 0.3$ \\
\hline Stigmastanol & $8.0 \pm 2.0$ & $8.9 \pm 1.0$ & $10.7 \pm 0.8$ \\
\hline $5 \beta$-Stigmastanol & $9.6 \pm 0.8$ & $7.8 \pm 0.1$ & $10.6 \pm 1.0$ \\
\hline Sitostanol & $13.1 \pm 1.8$ & $13.9 \pm 1.2$ & $21.7 \pm 0.3$ \\
\hline 24-Ethylcoprostanol & $7.6 \pm 1.7$ & $7.5 \pm 0.5$ & $9.6 \pm 1.3$ \\
\hline 24-Ethylepicoprostanol & $13.4 \pm 0.2$ & $9.4 \pm 0.5$ & $11.4 \pm 0.6$ \\
\hline Total & $297.6 \pm 91.7$ & $175.9 \pm 19.7$ & $145.0 \pm 17.5$ \\
\hline Escherichia coli & $67 \pm 0$ & $220 \pm 0$ & $9150 \pm 9687$ \\
\hline
\end{tabular}

